\title{
Research of semi-integrated and fully coupled analysis methods of a fixed bottom OWT
}

\author{
B. Wang ${ }^{1, a}$, W. H. Wang ${ }^{2}$, X. Li $i^{2, b}, Y . \mathrm{Li}^{3}$ \\ ${ }^{1}$ Powerchina Huadong Engineering Corporation Limited, Hangzhou 310014, China \\ awang_b6@ecidi.com \\ ${ }^{2}$ State Key Lab of Coastal and Offshore Engineering, Dalian University of Technology, Dalian \\ 116024, China \\ blixin@dlut.edu.cn \\ ${ }^{3}$ Chinese-Deutsch Institute for Applied Engineering, Zhejiang University of Science and \\ Technology, Hangzhou, 310023, China
}

\begin{abstract}
KEYWORD: offshore wind turbine; FAST; SACS; semi-integrated analysis method; fully coupled analysis method

ABSTRACT: The semi-integrated analysis method was used extensively in the design of offshore wind turbine in China. Recent researches have proved that the wave loads and sub-structure responses have significant effects on the aerodynamic loads of the blades especially in the operation conditions. In order to take these effects for OWT design into account, the fully coupled analysis method was presented. Using Fortran language, a FAST-SACS joint analysis module was developed to carry out time history verification of internal forces of sub-structure member. The comparisons between fully couple and semi-integrated analysis method are performed.
\end{abstract}

\section{RESEARCH BACKGROUND}

\section{Introduction}

The offshore wind energy plays an important role in renewable energy sources research. There are some word class offshore wind farm are being under construction in China. The fixed bottom substructure were widely used in offshore wind turbine design in China. In recent years significant efforts have been made to improve fixed bottom sub-structure design method.

Böker C. (2010) developed a finite element code and coupled with Flex5 to research the fixed bottom OWT analysis method and further investigate the excitation of local dynamics in fully coupled model. Yan F., et al. (2012) based on NREL 5MW wind turbine and a spar researched the differences of coupled and limited coupled methods, they found that the heave result of limited coupled model is much greater that the couple model. Gutierrez J., et al (2013) presented a new engineering software based on FAST and another commercial software in order to perform optimization design of offshore wind turbine, an important advantage is the parametric design capability. Burn (2011) research the influence of different foundation modeling methodologies on the dynamic response of offshore wind turbine sub-structure. Cordle A., et al (2011) researched the relative importance of the various external conditions in OWT design based on a jacket OWT subjected to wind and wave loading.

\section{The semi-integrated analysis method}

Step 1, derive the equivalent stiffness and mass matrixes at the flange point (transfer point-TP) on the basis of FE model of OWT sub-structure, such as monopile, tripod, pentapod or jacket. Step 2, calculate aerodynamic loads and wind turbine loads of transfer point, establish FE model of bladehub-nacelle-tower partial structure in the aero-elastic analysis code, model the sub-structure and the foundation using the equivalent stiffness and mass matrixes in this step. Step 3, apply the transfer point wind turbine loads to the FE model in step 1, in order to update the equivalent stiffness matrix. Figure 1 illustrates the analysis procedure of the semi-integrated analysis method. 


\section{The fully coupled analysis method}

Step 1, establish the integrated model of the OWT, define the tower base flange point as transfer point, establish FE model of the rotor hub nacelle (RNA) and tower in the aero-elastic analysis package, establish the sub-structure FE model in the FE analysis package. Step 2, set up environment load conditions, such as wave wind current, and apply control strategies to the integrated model. Step 3, perform time domain analysis, calculate structure responses under the wave wind load environment loads. Figure 2 illustrates the analysis procedure of the fully coupled analysis method.

\begin{tabular}{|c|}
\hline $\begin{array}{c}\text { FE analysis } \\
\text { software }\end{array} \quad \begin{array}{c}\text { Aero-elastic analysis } \\
\text { software }\end{array}$ \\
\hline
\end{tabular}

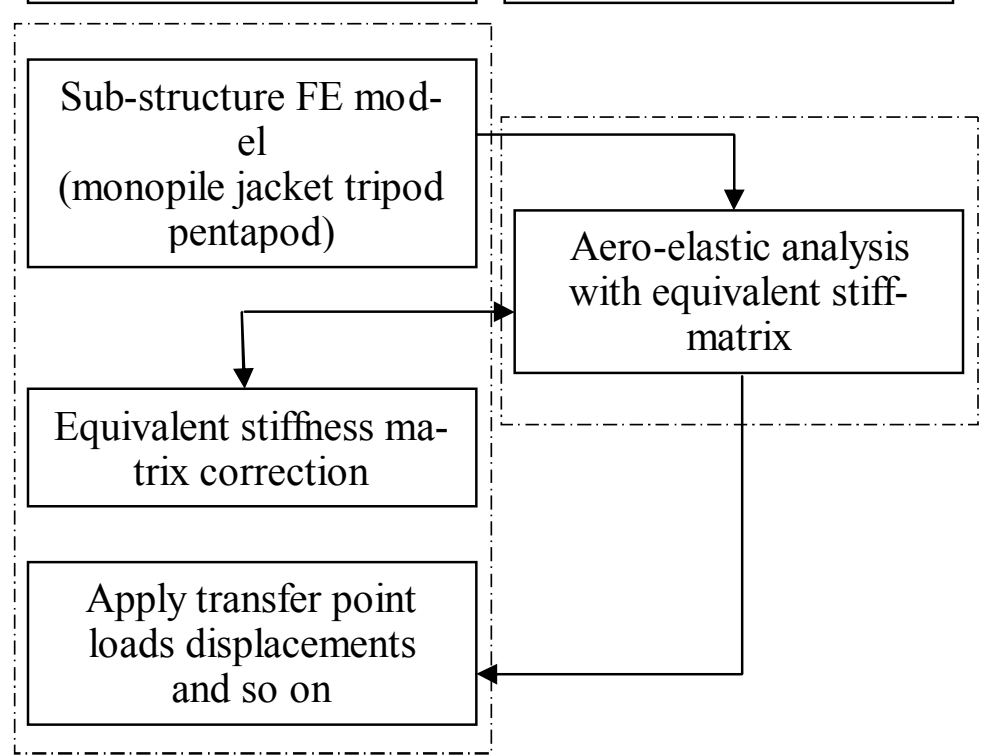

Figure 1. Schematic flow chart of semi-integrated analysis method

\begin{tabular}{|c|}
\hline $\begin{array}{c}\text { FE analysis } \\
\text { package }\end{array}$ \\
$\begin{array}{c}\text { Aero-elastic analysis } \\
\text { package }\end{array}$ \\
\hline
\end{tabular}

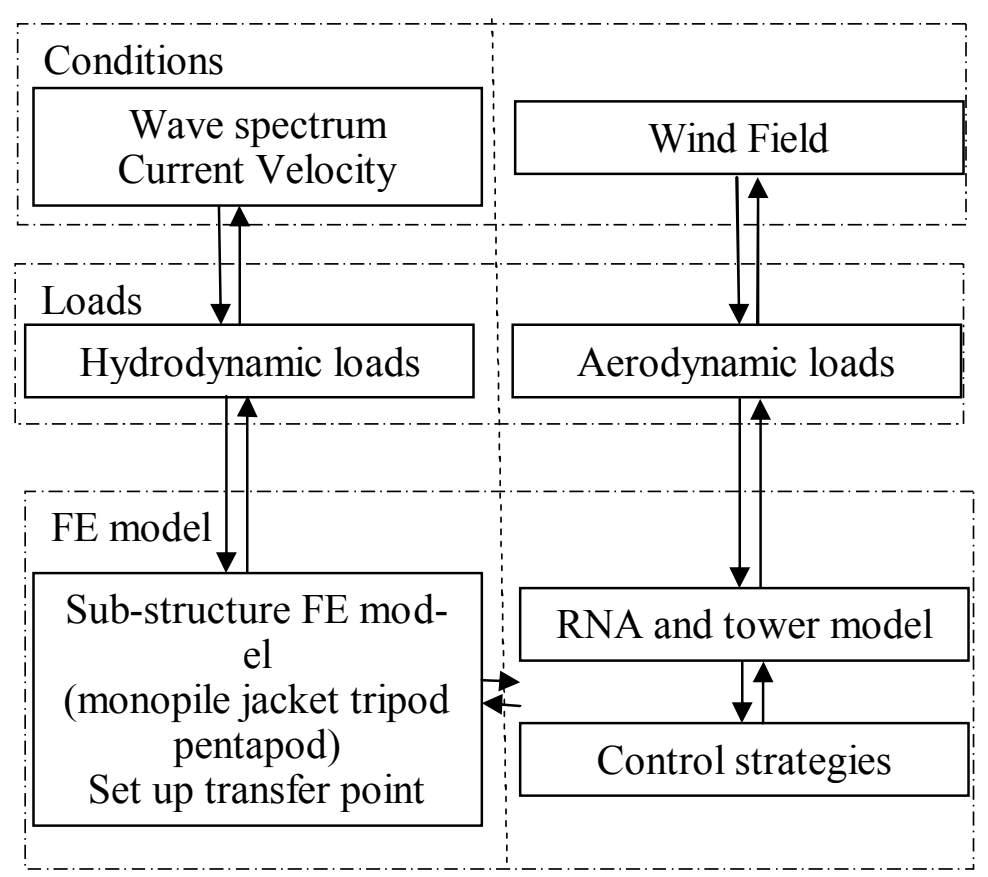


Figure 2. Schematic flow chart of fully coupled analysis method

\section{NUMERICAL ANALYSIS OF HW 5MW OWT}

\section{Basic Parameters of HW 5MW OWT}

Combined the NREL 5MW baseline wind turbine and its tower with the pentapod sub-structure and foundation of a practical OWT, an integrated structure system of OWT, named HW 5MW OWT, is suggested. The upper structure configuration of HW 5MW is the same with the NREL 5MW. The basic parameters of upper structure are listed in Table 1. Table 2 lists environmental parameters for wind and wave loads calculation. Figure 3 illustrates pentapod dimensions of HW 5MW OWT.

Table 1. Upper structure basic parameters

\begin{tabular}{ll}
\hline Parameters & Values \\
\hline Rating & $5 \mathrm{MW}$ \\
Rotor, hub diameter & $126 \mathrm{~m}, 3 \mathrm{~m}$ \\
Hub height & $90 \mathrm{~m}$ \\
Cut in, rated, cut out wind speed & $3 \mathrm{~m} / \mathrm{s}, 11.4 \mathrm{~m} / \mathrm{s}, 25 \mathrm{~m} / \mathrm{s}$ \\
Cut in, rated rotor speed & $6.9 \mathrm{rpm}, 12.1 \mathrm{rpm}$ \\
Overhang, shaft tilt, precone & $5 \mathrm{~m}, 5^{\circ}, 2.5^{\circ}$ \\
Rotor mass & $110,000 \mathrm{~kg}$ \\
Nacelle mass & $240,000 \mathrm{~kg}$ \\
\hline
\end{tabular}

Table 2. Environmental conditions

\begin{tabular}{ll}
\hline Parameters & Values \\
\hline Wind speed, reference height & $8.0 \mathrm{~m} / \mathrm{s}, 90 \mathrm{~m}$ \\
Water depth & $24.75 \mathrm{~m}$ \\
Wave height, wave period & $7.15 \mathrm{~m}, 8.21 \mathrm{~s}$ \\
\hline
\end{tabular}

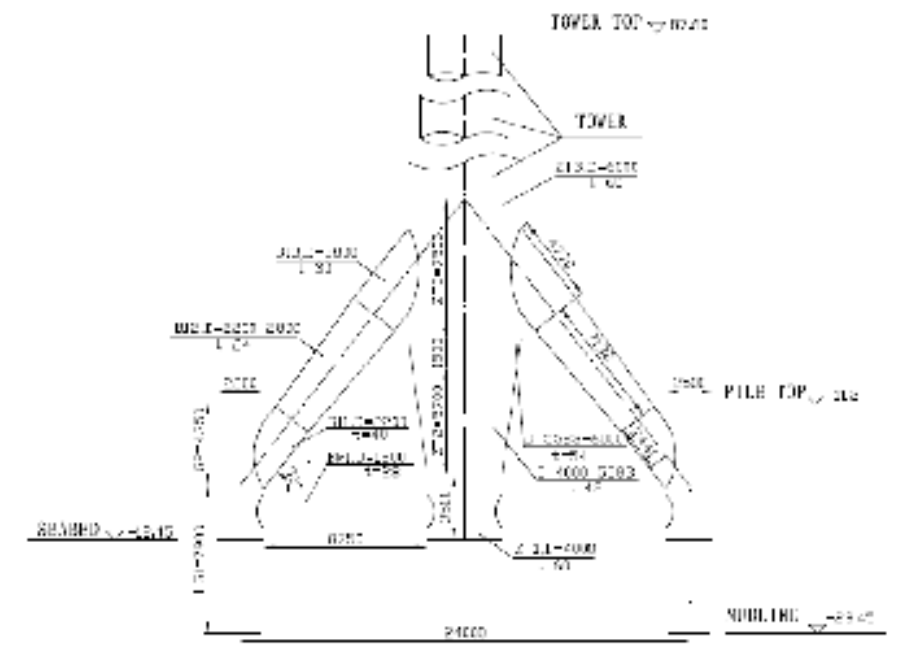

Figure 3. Pentapod structure of HW 5MW OWT (unit: elevation, m, dimension, mm)

\section{FAST-SACS Joint Analysis Module}

To apply fully coupled analysis method in fixed bottom offshore wind turbine time domain verification, the FAST-SACS joint analysis module was developed using Fortran language. This joint analysis module developed is on the basis of FAST V8.0 and SACS V5.7. Figure 4 illustrates the analysis procedure of this module. 


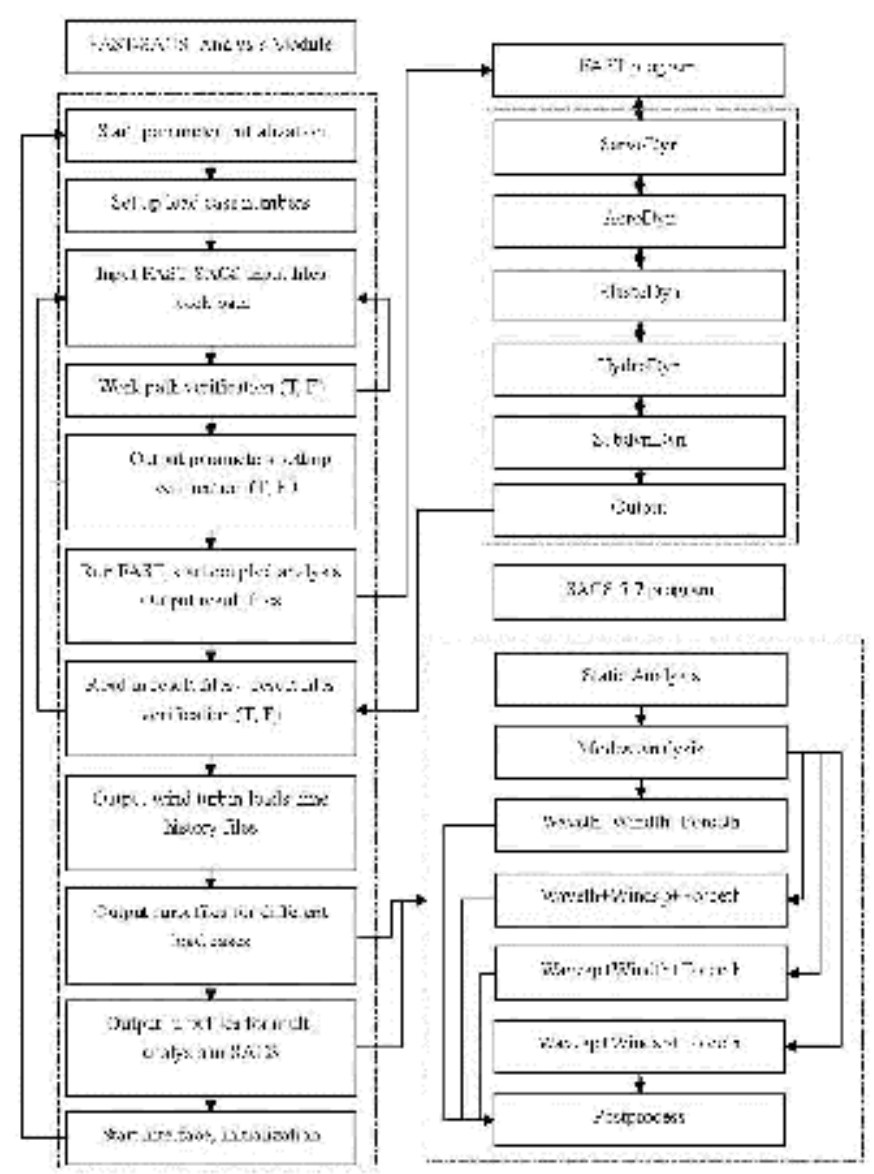

Figure 4. Schematic flow chart of FAST - SACS joint analysis module

Numerical Model of HW 5MW OWT

\section{The semi-integrated analysis numerical model}

Figure 5 depicts the pentapod FE model in SACS, the equivalent stiffness and mass matrixes were derived based on this model. Figure 6 and Figure 7 present the equivalent stiffness and mass matrixes.

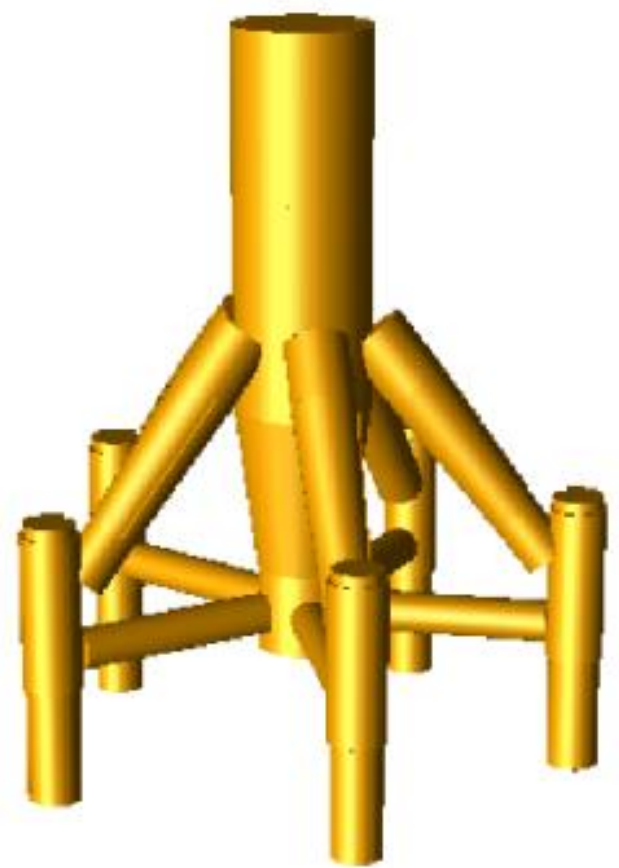

Figure 5. Pentapod structure FE model in SACS 


KBtp $=\left[\begin{array}{cccccc}0.53 E 8 & 0.64 E 4 & 0.12 E 6 & 0.11 E 6 & -0.55 E 9 & 0.15 E 6 \\ -0.12 E 5 & 0.53 E 8 & 0.48 E 4 & 0.55 E 9 & 0.95 E 5 & 0.40 E 5 \\ 0.12 E 6 & -0.40 E 4 & 0.33 E 10 & -0.40 E 6 & -0.21 E 7 & -0.43 E 6 \\ -0.88 E 4 & 0.55 E 9 & -0.33 E 6 & 0.58 E 11 & -0.54 E 6 & 0.13 E 6 \\ -0.55 E 9 & -0.81 E 5 & -0.21 E 7 & -0.16 E 7 & 0.58 E 11 & -0.30 E 7 \\ 0.26 E 5 & 0.13 E 6 & -0.42 E 6 & 0.26 E 7 & -0.17 E 7 & 0.66 E 10\end{array}\right]$

Figure 6. Equivalent stiffness matrix at TP

$M B t p=\left[\begin{array}{cccccc}0.56 E 6 & -0.17 E 2 & -0.22 E 3 & -0.19 E 3 & -0.48 E 7 & -0.31 E 3 \\ -0.17 E 2 & 0.57 E 6 & -0.30 E 2 & 0.48 E 7 & 0.11 E 3 & -0.11 E 3 \\ -0.22 E 3 & -0.30 E 2 & 0.32 E 6 & -0.32 E 3 & 0.22 E 4 & 0.69 E 3 \\ -0.19 E 3 & 0.48 E 7 & -0.32 E 3 & 0.44 E 8 & 0.12 E 4 & -0.26 E 4 \\ -0.48 E 7 & 0.11 E 3 & 0.22 E 4 & 0.12 E 4 & 0.44 E 8 & 0.56 E 4 \\ -0.31 E 3 & -0.11 E 3 & 0.69 E 3 & -0.26 E 4 & 0.56 E 4 & 0.19 E 8\end{array}\right]$

Figure 7. Equivalent mass matrix at TP

\section{The fully coupled analysis numerical model}

The fully coupled analysis model was established in FAST, the RNA and tower model were modeled in ElastoDyn module, the pentapod structure was modeled in SubDyn module, the foundation was modeled by equivalent pile in the SubDyn.

The equivalent pile length was determined by the similarity of the $1^{\text {st }}$ and $2^{\text {nd }}$ integrated structure frequencies. According to this principle, the equivalent pile length was set as 8.3 times pile diameter. The integrated prototype $1^{\text {st }}$ and $2^{\text {nd }}$ frequencies are $0.3209 \mathrm{~Hz}, 0.3214 \mathrm{~Hz}$, the equivalent structure $1^{\text {st }}$ and $2^{\text {nd }}$ are $0.3206 \mathrm{~Hz}, 0.3211 \mathrm{~Hz}$.

Figure 8 presents the procedure of fixed bottom OWT coupled analysis in FAST.

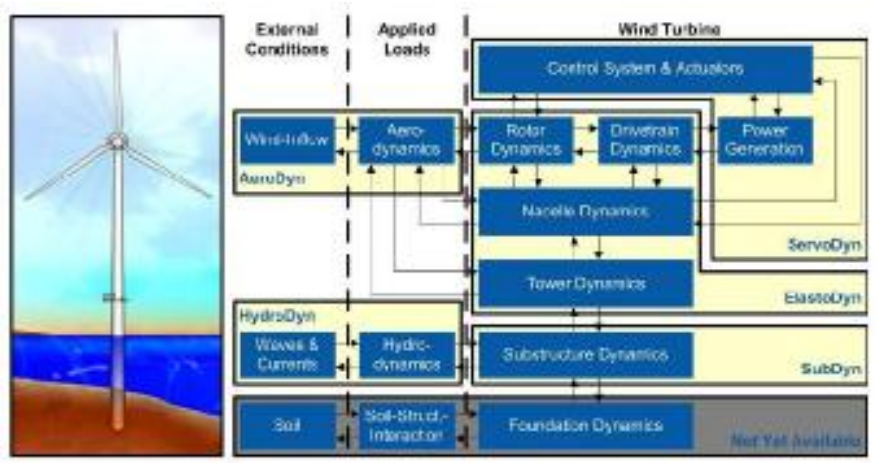

Figure 8. Couple analysis of fixed bottom OWT in FAST, taken from FAST v8.10.00 user 's guide

So the semi-integrated analysis model was modeled in FAST V7.0 and SACS separately, the fully coupled analysis model were modeled in FAST V8.0. By using the FAST-SACS joint analysis module, the analysis method differences research was performed.

\section{NUMERICAL RESULTS OF HW 5MW FE ANALYSIS}

\section{Aerodynamic loads comparison}

Based on the aero-elastic analysis package, the aerodynamic loads of semi-integrated and coupled model were calculated. Figure 9 presents the comparison result of the thrust force. 


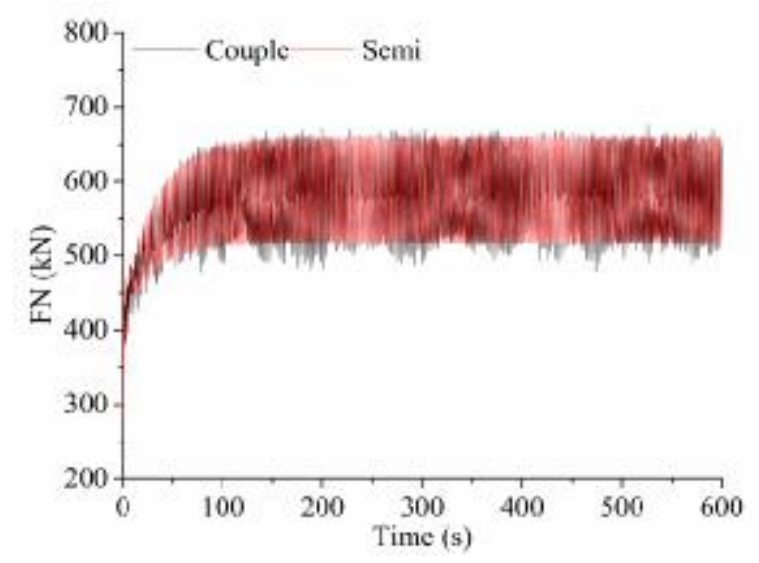

Figure 9. Thrust force comparison

Figure 9 (a) present that the thrust forces of the two models are almost equality. The coupled model result has a wider amplitude variation scope, due to the differences in the sub-structure torsion stiffness.

\section{Pentapod member internal forces comparison}

In order to further research the differences between two models, the substructure member internal forces comparison results are listed in Figure 10. The member number and local coordinate system can refer to Figure 11.

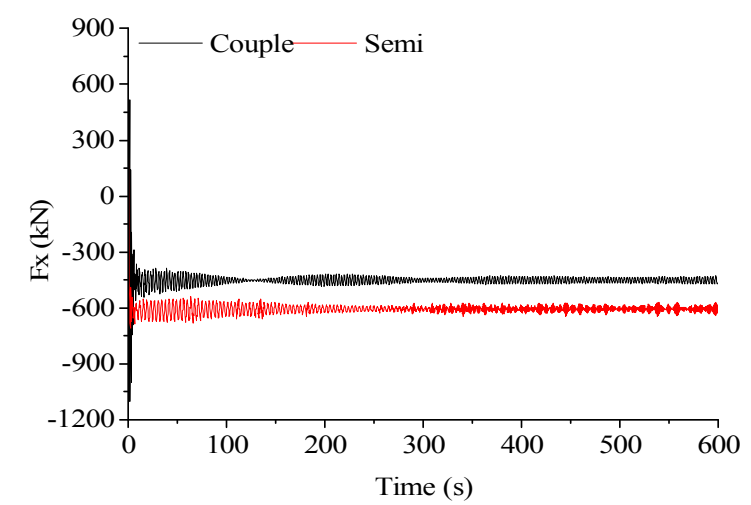

(a) Joint 8001-Fx

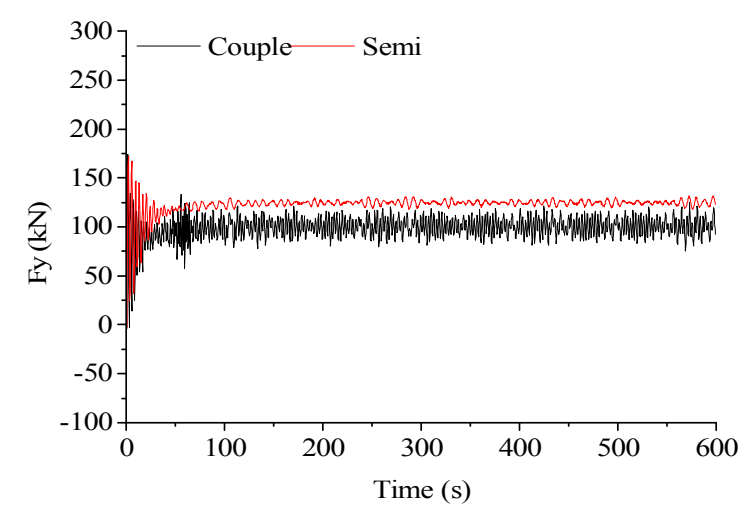

(b) Joint 8001-Fy 


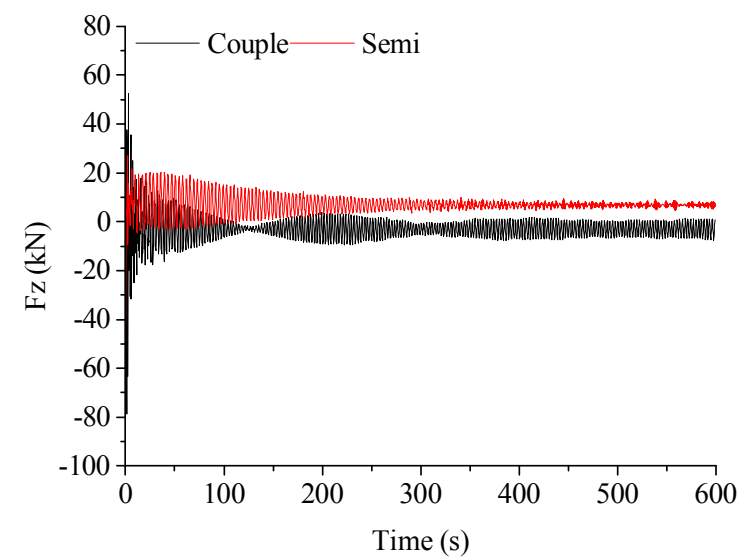

(c) Joint $8001-\mathrm{Fz}$

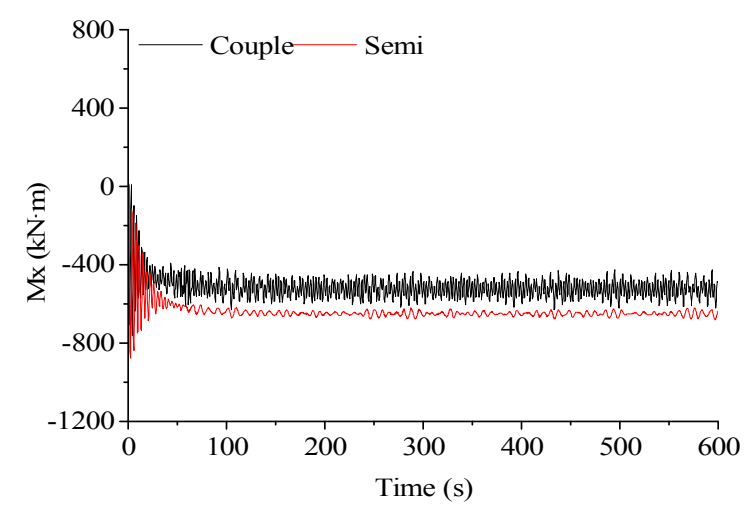

(d) Joint 8001-Mx

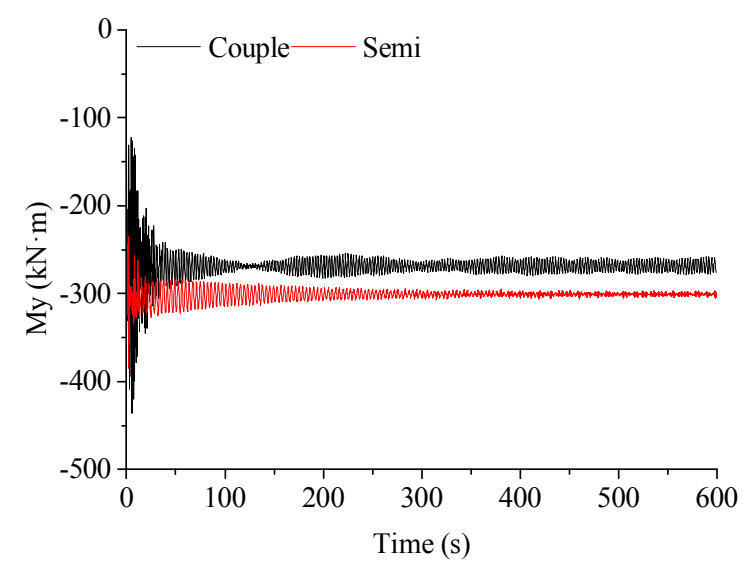

(e) Joint 8001-My

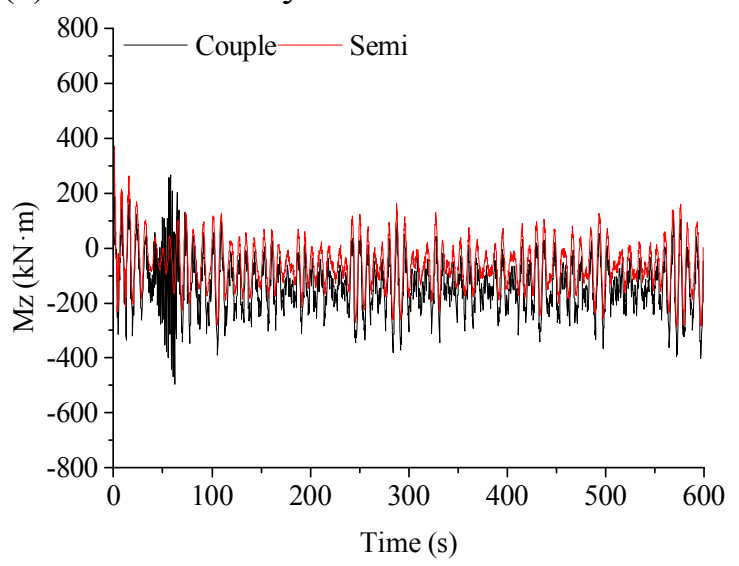

(f) Joint $8001-\mathrm{Mz}$

Figure 10. Member 8001-9001 joint 8001 comparison results 
Figure 10 depicts the differences of semi-integrated and coupled model analysis results of pentapod member internal forces. The variation of internal forces are same with the thrust loads, the semiintegrated model have greater mean value than the coupled model, while the couple model has a wider amplitude, such as Figure 10 (b) (c) (d). Figure 12 - Figure 17 illustrate the comparison results of statistic values.

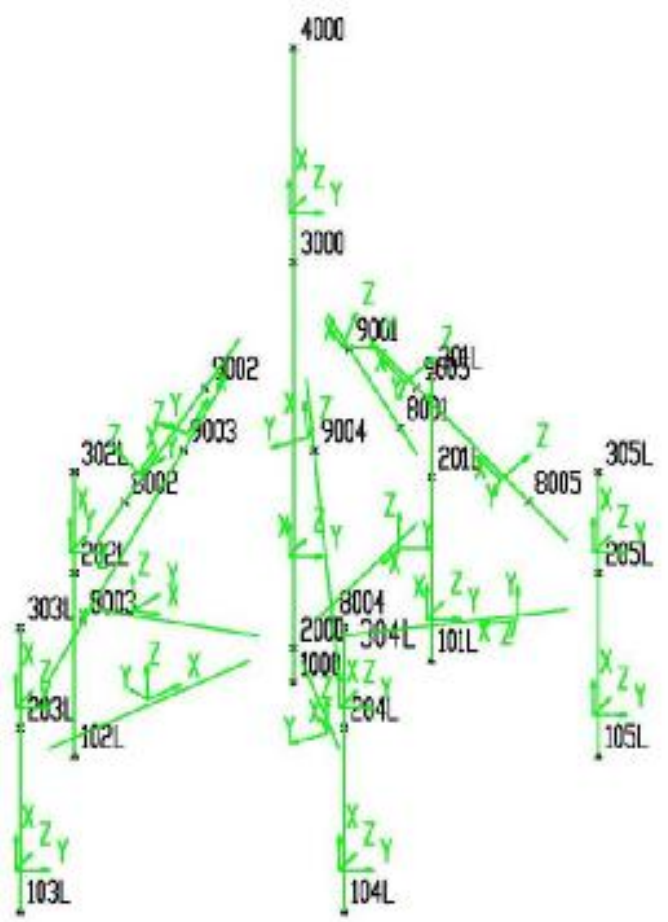

Figure 11. Member local coordinate system

Figure 12 and Figure 13 depict the comparison results of Fx, such as joint 8001, the maximum minimum mean values of the semi-integrated model are $-540.8 \mathrm{kN}-682.9 \mathrm{kN}-606.5 \mathrm{kN}$, the variation scope is $145.1 \mathrm{kN}$, while the coupled model results are $-386.1 \mathrm{kN}-524.0 \mathrm{kN}-451.7 \mathrm{kN}$, the variation scope is $137.9 \mathrm{kN}$. So the mean value and variation scope of the semi-integrated model are $34 \%$ and 5\% larger than the coupled model respectively.

Figure 14 and Figure 15 depict the comparison results of My, such as joint 8003, the maximum minimum mean values of the semi-integrated model are $333.05 \mathrm{kN} \cdot \mathrm{m} 28.86 \mathrm{kN} \cdot \mathrm{m} 176.59 \mathrm{kN} \cdot \mathrm{m}$, the variation scope is $304.19 \mathrm{kN} \cdot \mathrm{m}$, while the coupled model results are $366.26 \mathrm{kN} \cdot \mathrm{m}-27.36 \mathrm{kN} \cdot \mathrm{m}$ $167.48 \mathrm{kN} \cdot \mathrm{m}$, the variation scope is $393.62 \mathrm{kN} \cdot \mathrm{m}$. The mean value of the semi-integrated model is $5 \%$ larger than the coupled model, while the variation scope of the semi-integrated model is $30 \%$ less than the coupled model.

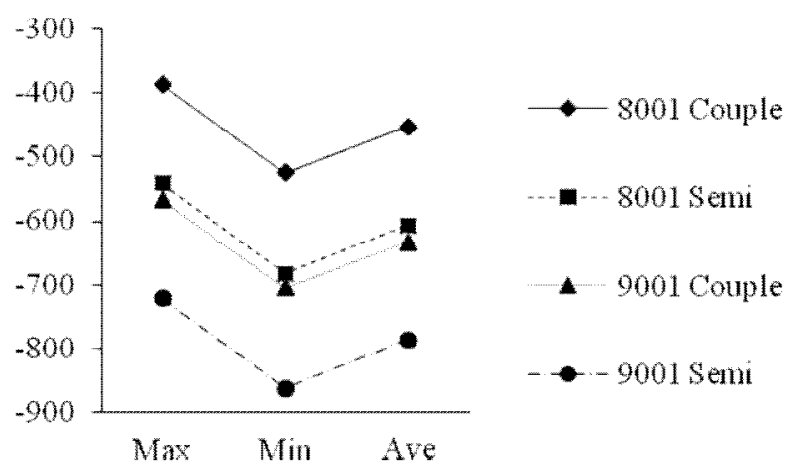

Figure 12. Member 8001-9001 internal force Fx statistic values comparison 


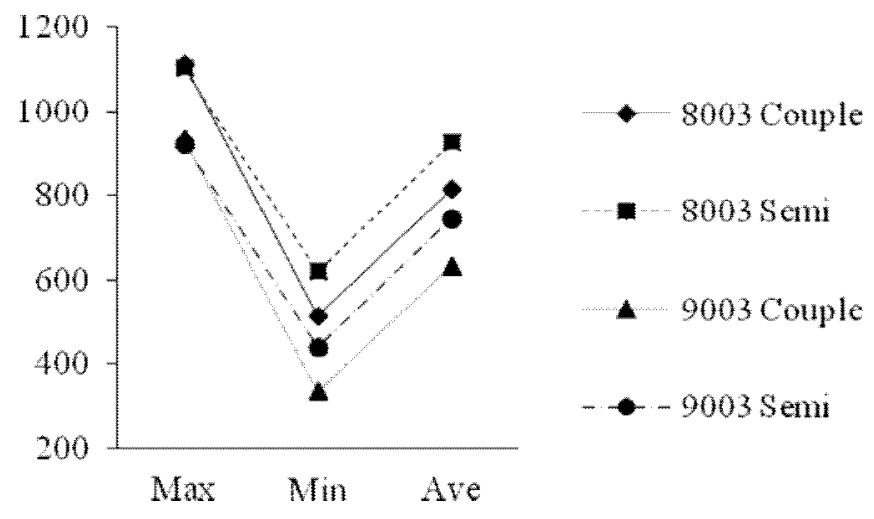

Figure 13. Member 8003-9003 internal force Fx statistic values comparison

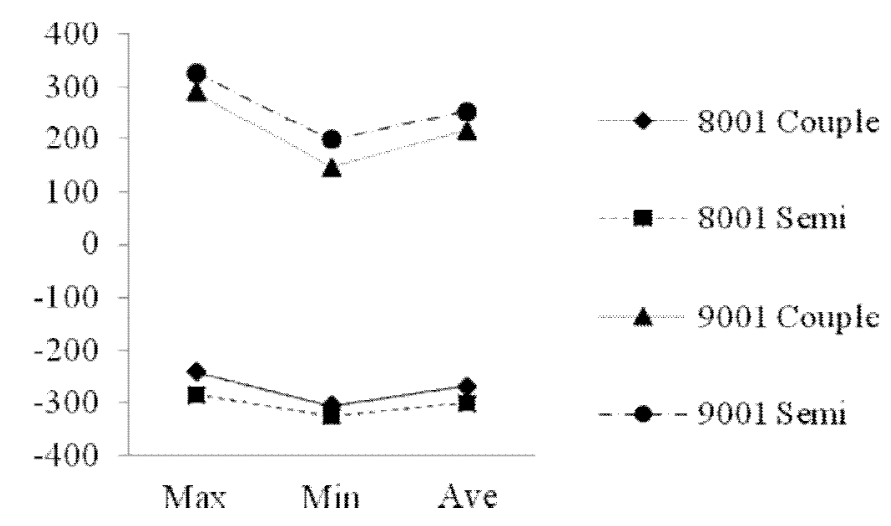

Figure 14. Member 8001-9001 internal force My statistic values comparison

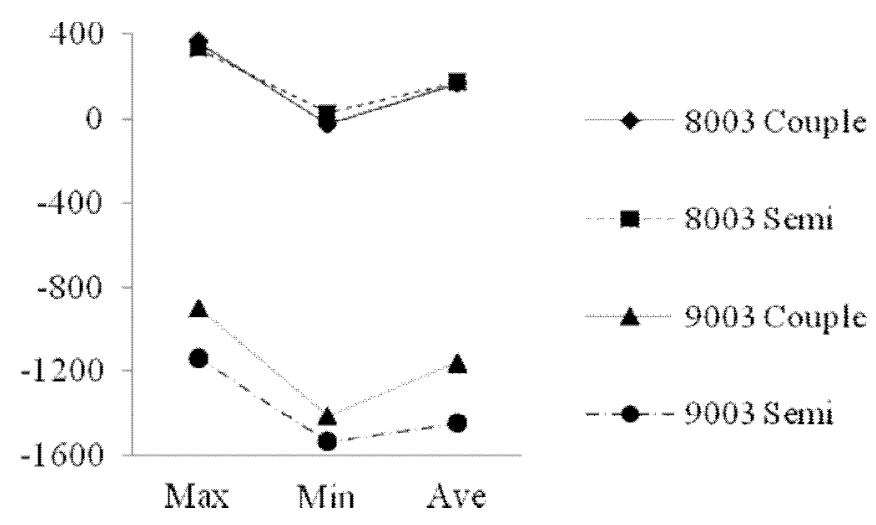

Figure 15. Member 8003-9003 internal force My statistic values comparison

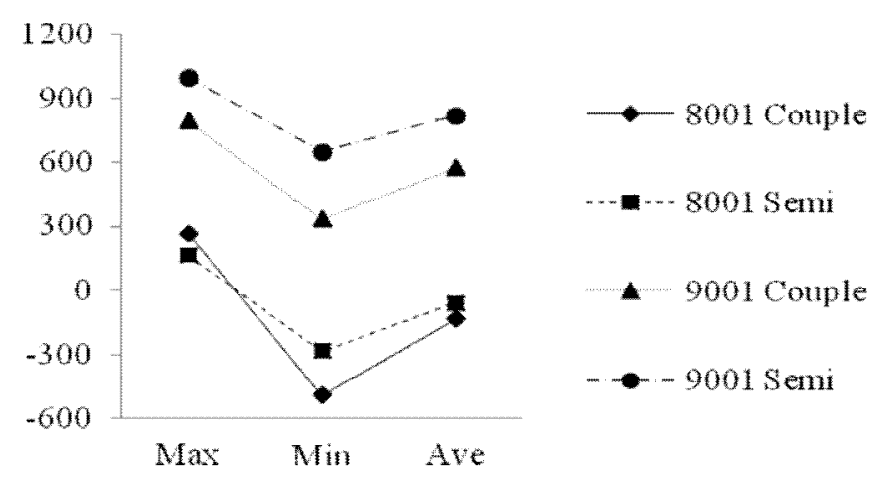

Figure 16. Member 8001-9001 internal force Mz statistic values comparison 


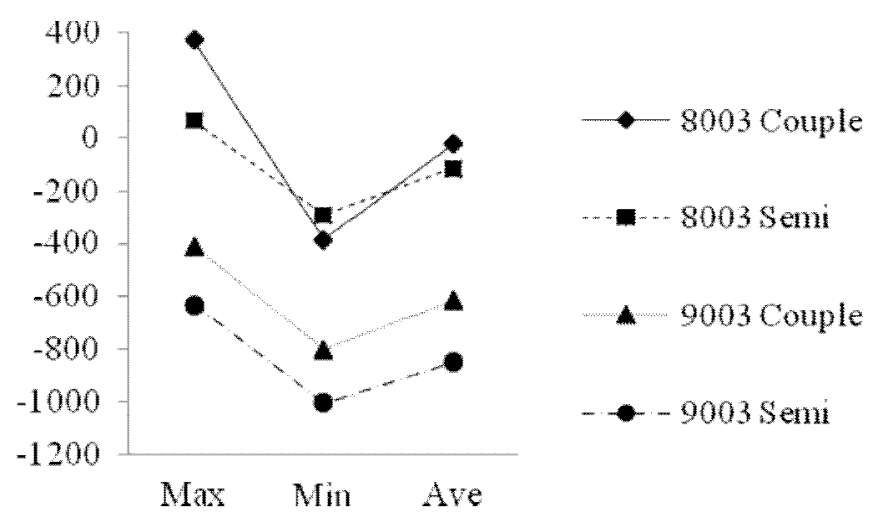

Figure 17. Member 8003-9003 internal force Mz statistic values comparison

\section{CONCLUSIONS}

Based on the HW 5MW OWT, the differences between semi-integrated and fully coupled analysis were researched. Comparisons of aerodynamic loads, TP wind turbine loads and pentapod member internal forces show that variation range of the results from semi-integrated model may exceed those from coupled model in most cases, but for internal forces of some member joints, the couple analysis model may give the larger results.

\section{ACKNOWLEDGEMENT}

This work is funded by the National Natural Science Foundation of China (Grant No. 51121005), and supported by the Science Foundations of Powerchina Huadong Engineering Corporation Limited (No. KY120228-03-07 and KY2014-02-41) and the Open Fund Project of State Key Lab of Coastal and Offshore Engineering in Dalian University of Technology (No. LP1413). Their financial supports are gratefully acknowledged.

\section{REFERENCES}

[1] Cord Böker. Load simulation and local dynamics of support structures for offshore wind turbines. Aachen, 2010.

[2] Fasuo Yan, Cheng Peng, Jun Zhang, Dagang Zhang. Dynamic response of an offshore wind turbine system using coupled and limited coupled methods. International conferences on ocean, offshore and arctic engineering, Brazil: 2012.

[3]José E. Gutierrez, Blas Zamora, Julio García, María R. Peyrau. Tool development based on FAST for performing design optimization of offshore wind turbines: FASTLognoter. Renewable Energy, 2013, 55: 69-78.

[4] Van Burn. Effect of foundation modeling methodology on the dynamic response of offshore wind turbine support structures. International conference on ocean, offshore and arctic engineering, Netherlands: 2011.

[5] Anderw Cordle, Graeme McCann, Wybren de Vries. Design drives for offshore wind turbine jacket support structures. International conference on ocean, offshore and arctic engineering, Netherlands: 2011.

[6] Sandy Butterfield, Walter Musial, George Scott. Definition of a 5-MW reference wind turbine for offshore system development. Golden, CO: National Renewable Energy Laboratory, 2009.

[7] Jason M. Jonkman, Marshall L. Buhl. FAST user's guide. National Renewable Energy Laboratory, CO, Technical Report No. NRRL/EL-500-38230, 2005.

[8] David Laino, A. Craig Hansen. User's guide to the wind turbine aerodynamics coputer software AeroDyn. Windward Engineering, LC, Salt Lake City, UT:2002. 
[9] Bonnie Jonkman, Jason Jonkman. FAST v8.10.00 user's guide. National Renewable Energy Laboratory, CO: 2015.

[10] R. Damiani, J. Jonkman, G. Hayman. SubDyn user's guide and theory manual. National Renewable Energy Laboratory, CO: 2015.

[11] J. Jonkman, A. Robertson, G. Hatman. HydroDyn user's guide and theory manual. National Renewable Energy Laboratory, CO: 2015. 